\title{
ENTREVISTA
}

\section{Significación Sociocultural de la Masonería en la ciudad de Guantánamo. 1900-1958}

La investigadora Suray Olivares Pérez ha defendido una Tesis de grado, cuyo título es "Significación Sociocultural de la Masonería en la ciudad de Guantánamo. 1900-1958". En la Universidad de Guantánamo, en Cuba, el 4 de julio de 2014, bajo la dirección de la Dra. C Migdalia Tamayo Téllez. Suray Olivares Pérez nació en 1986, en Cuba.

La autora nos ha concedido la siguiente entrevista.

¿Cuáles fueron los motivos que le llevó a enfocar su investigación hacia la Masonería?

El primer motivo fue un trabajo para el examen final de una asignatura en el transcurso de mi carrera universitaria, este fue el primer encuentro con la Masonería, casi de manera obligada. A este motivo le sobrevino el interés que el tema fue despertando en mí dando al traste con un fuerte desconocimiento que sobre el mismo aún existe de manera general en la sociedad, a pesar de la fuerte presencia masónica en la ciudad y provincia Guantánamo en general.

¿Cuáles fueron las fuentes que ha utilizado?

Teniendo en cuenta lo difícil que se hacía trabajar el tema debido a las características propias de la institución fraternal, así como la escasa literatura publicada en nuestro país, las principales fuentes consultadas fueron entrevistas concedidas por fraternales de las diferentes logias de la ciudad, así como la del historiador de la ciudad de Guantánamo. Se consultaron además revistas y periódicos de la época, entre ellas la revista Ariel, órgano principal de la Masonería en la ciudad de Guantánamo durante la etapa de estudio. Se consultó la literatura de ficción "El Símbolo Perdido", del escritor e investigador norteamericano Dan Brown, el libro "Historia de la Francmasonería en Cuba. Seis ensayos", del Dr e investigador cubano Eduardo Torres Cuevas, una de las principales fuentes que mayor aporte brindó a mi investigación, además de boletines y documentos históricos facilitados por los fraternales, la Gran Logia de Cuba y el Supremo Consejo de la República de Cuba.

¿Cuáles fueron las principales dificultades con las que se ha encontrado? ¿Cómo las ha superado?

Además del desconocimiento anteriormente planteado, del criterio distorsionado que sobre la institución existe, la escasa bibliografía, y el escepticismo de la mayoría de las personas a las que les planteaba de qué iba mi investigación, el principal obstáculo, devenido más tarde en total ventaja, fue el ser mujer. Presentarme en una Logia en la ciudad de Guantánamo y decir que estaba investigando sobre la Masonería se convirtió en todo un reto. Esos primeros meses de búsqueda de información, de entrevistas, de fechas pactadas que luego se suspendían por parte de los entrevistados, esa lucha incesante porque me tomaran verdaderamente en serio, porque se interesaran por mi investigación, por ambos lados, el fraternal y el profano, ese momento en que mi tutora 
me comunicó que tenía que ir al Supremo Consejo, que tenía que ir a la Gran Logia, teniendo que salir de la provincia, creo que esas fueron las principales dificultades en el proceso de investigación, que obviamente han sido totalmente superadas en primer lugar por mi obstinación, por mi necesidad imperiosa de creer en una idea y luchar por ella, por la seriedad con que asumí la tarea, la constancia, y pues la buena voluntad con la que me acogieron en todos los lugares que fui. La enorme ayuda brindada por el Supremo Consejo de la República de Cuba, en la figura de su Soberano Gran Comendador, señor Lázaro Cuesta, así como de todos los altos dignatarios de la Masonería en la provincia Guantánamo.

¿Cuáles fueron las principales problemáticas históricas que su trabajo ha resuelto?

La principal problemática que resolvió mi investigación, en primera instancia fue desmitificar el halo de intrigas y misterios que sobre la institución masónica recaían. Y en segundo lugar, llenar un espacio en la historia de la ciudad de Guantánamo que había quedado vacío durante mucho tiempo y que se le debía a la Masonería. Demostrar de manera cronológica con hechos y sucesos la fuerza con la que influyó la Masonería desde los ámbitos histórico, como social y cultura en la ciudad de Guantánamo en el periodo de estudio era algo que se hacía por primera vez en la Provincia con la entera colaboración de la fraternidad mediando. El documento donde se pudo recopilar toda esta información sirve hoy como material de consulta para estudiantes y profesores interesados en conocer la labor de la fraternidad masónica.

¿Por favor, podría resumir la esencia de su Tesis en dos líneas?

Hermandades como la masónica han sido blanco de acusaciones a las que se les adjudica tener un carácter diabólico y subversivo debido al alto grado de secretismo y hermeticidad que las envuelve, despejar el halo de intriga y misterios que durante siglos la ha sobrevolado e impide revelar cuánto aportó a la formación de la cultura cubana y guantanamera devino en pretexto para la indagación.

¿Cuáles fueron las lecciones, a todos los niveles, personal y profesional, que usted ha deducido de su experiencia investigativa?

Las lecciones fueron muchas. Investigar sobre un tema al que todos le temían, por el que muchos dudaron en saber si podría o no lograr aglutinar información suficiente para una Tesis se convirtió en todo un reto, que aunque en algunos momentos me hizo dudar, al mismo tiempo me daba fuerzas para seguir adelante, me convencía de que lo que estaba haciendo valía la pena. Aprendí que la constancia, la paciencia y el respeto por lo que se hace, son las claves del éxito para cualquier investigación, además de ser las cartas de presentación del investigador, y por supuesto, lo esencial (como diría SaintExupery) que es invisible a los ojos, la lección mayor fue saber que la Masonería va más allá de las simples trivialidades de la seña, el toque o la palabra, hecho que quedó demostrado cuando bajo la aprobación de los grandes dignatarios masónicos de la Provincia Guantánamo, se aprobó de manera unánime la defensa de mi tesis dentro del templo de la Logia Madre de la Masonería en Guantánamo.

¿Ahora, cuáles son sus proyectos profesionales? 
En estos momentos estoy escribiendo un primer libro con el contenido de mi investigación para que el material no quede solo a disposición de estudiantes y profesores sino que pueda ser consultado por profanos y fraternales que se encuentren atraídos por el tema, no solo para los de la Provincia donde vivo sino de manera general para el País, sería este el primero de tres que tengo pensados escribir sobre el tema masónico siempre abordando las características de Guantánamo. Además estoy por comenzar la Escuela de Formación Doctoral en la que pretendo trabajar si bien con otro enfoque, pero la misma línea temática.

¿Quisiera destacar algún aspecto que no se ha contemplado y que usted consideraría digno de reseñar?

Pues para los lectores tal vez resulte insistente mi necesidad de escribir sobre Guantánamo cuando bien pudiera abarcar el territorio nacional, más, además de ser mi lugar de nacimiento, es necesario destacar que Guantánamo es una de las provincias más fraternal de Cuba, que en este pequeñito lugar existen dos órdenes fraternales que no se encuentran en el resto del país, y además, está el puntal de que la Masonería entró a Cuba por la provincia Guantánamo, específicamente por la ciudad de Baracoa, la primera villa fundada en Cuba. De ahí que quede mucha tela por cortar si de Masonería se trata en esta provincia.

Esta entrevista se efectúo de forma telemática el 4 de febrero de 2015.

Autores de la entrevista: Ricardo Martínez Esquivel e Yván Pozuelo Andrés, Director y Editor de la REHMLAC. 